\title{
Sport, masculinity and gender relations
}

\author{
Arnaldo Spallacci \\ Professor Emeritus of Sociology, University of Modena and Reggio-Emilia, Bologne, Italy
}

\section{abstract}

Key words: sport, masculinity, Italian men, gender relations, body image.

\section{article details}

Article statistics: Word count: 4,700; Tables: 0; Figures: 0; References: 19

Received: June 2020; Accepted: August 2020; Published: November 2020

Full-text PDF: http://www.balticsportscience.com

Copyright ๑ Gdansk University of Physical Education and Sport, Poland

Indexation: Celdes, Clarivate Analytics Emerging Sources Citation Index (ESCI), CNKI Scholar (China National Knowledge Infrastructure), CNPIEC, De Gruyter - IBR (International Bibliography of Reviews of Scholarly Literature in the Humanities and Social Sciences), De Gruyter - IBZ (International Bibliography of Periodical Literature in the Humanities and Social Sciences), DOAJ, EBSCO - Central \& Eastern European Academic Source, EBSCO - SPORTDiscus, EBSCO Discovery Service, Google Scholar, Index Copernicus, J-Gate, Naviga (Softweco, Primo Central (ExLibris), ProQuest - Family Health, ProQuest - Health \& Medical Complete, ProQuest - Illustrata: Health Sciences, ProQuest - Nursing \& Allied Health Source, Summon (Serials Solutions/ProQuest, TDOne (TDNet), Ulrich's Periodicals Directory/ulrichsweb, WorldCat (OCLC)

Funding: This research received no specific grant from any funding agency in the public, commercial, or not-for-profit sectors.

Conflict of interests: Corresponding author: Author has declared that no competing interest exists.

Professor Arnaldo Spallacci, Via Procaccini, 19, 40129 Bologna, Italy; phone: +39 3472556644; e-mail: arnaldo. spallacci@fastwebnet.it

Open Access License: This is an open access article distributed under the terms of the Creative Commons Attribution-Non-Commercial-NoDerivatives 4.0 International (https://creativecommons.org/licenses/by-nc-nd/4.0/), which permits use, distribution and reproduction in any medium, provided the original work is properly cited, the use is non-commercial and is otherwise in compliance with the license. 
Sport is part of the heritage of every man and woman, and its absence can never be compensated.

- Pierre de Coubertin ${ }^{1}$

\section{INTRODUCTION}

Sport represents one of the most relevant social activities in contemporary societies, and it has assumed a mass character that involves, for example in Western countries and Europe, more than half of the population, with an active participation of people regardless of age, gender, social or family status. Although, as we will show with specific data, not all social groups participate equally (for example, men are more present than women, young people more than the elderly), there is no denying that sport represents nowadays a central activity as budget, means of social aggregation, manifestation of values, passions, competition, solidarity, and tolerance.

First of all, the present paper tackles sport as an important typical masculine practice for the cultural and physical construction of masculinity, and consequently for the foundation of the patriarchal regime and female subordination; it is a paradigm based on a critical, often radically critical, theoretical and political vision towards male (which appears as essentially negative sex-gender), widespread at least until a few decades ago in the sociological-academic context and the popular literature.

From the end of the last century until now the approach has gradually widened, going beyond the classic perspective of sport being only a masculine socialization and competition; lately, other sport-related aspects have gained importance, for example the physical and mental well-being and the improvement of the body image. At the same time, the progressive entry of women into mass sport has been highlighted, which has produced a full change in its vision and practice, marking, eventually, also the internal male behaviours.

Therefore, the topic regarding men and sports and its evolution over the past 50 years must be placed and interpreted primarily within the general change in "gender relations" that has occurred mainly in the Western world. Secondly, from a certain point on, the topic of masculine sport must be connected to the transformation of male culture (i.e. the change of habits, behaviours, life goals, self-care), and to the emergence of new figures of masculinity which have largely replaced the stereotype of the patriarch, dominator, insensitive, violent man.

The increase in the relevance of sport has extended its presence also in the political and institutional fields; in the last half-century there has been a significant multiplication of documents created by various national public entities and not only. These documents (of which we will address to those elaborated by the European Union) examine and deepen the topic of sport and physical activities, the principles, the role of the subjects engaged in these activities, and the political and organizational guidelines from which different types of material supports and economic funds originate.

Sports and physical activities are periodically monitored to check the trends and evaluate their effectiveness, and thus to establish the political guidelines for their development. To understand the reality of sports in Europe, different especially between men and women, data from the Eurobarometer [1], a research centre that carries out periodic statistical surveys regarding the situation of sport and "physical activities" in EU countries, is reported in this paper.

Furthermore, the relationship between men and sport is addressed based on the analysis of different representations of the phenomenon essentially from a sociological point of view, starting from the 1970s until nowadays. We will also examine "gender relations," especially the relationships between males and females in the context of sports in order to

${ }^{1}$ Pierre de Coubertin (1863-1937), French pedagogue and historian, founder of the modern Olympic Games. 
understand how sport has contributed to the formation of a specific dominant male culture (sometimes called "hegemonic" masculinity [2, 3] in opposition to a more disadvantaged female culture and condition, not only in sport but also in society.

Basically, on the one hand, the paper aims to examine the dialectical relation between ideology and sports practice, and on the other hand, the cultural and physical construction of masculinity (the theme of the body plays a central role in this regard) related to the evolution of gender relations in society. All in a dynamic perspective, with great attention to change, especially the masculine one, in order to avoid remaining linked to traditional stereotypes, which eventually always reproduce the same visions and interpretations, thus denying the social change that is the very soul of sociology.

\section{SPORT AND SOCIOLOGY, THE SOCIAL ROLE OF SPORT}

Already in the 19th century, sociology became interested in sport, even if still in a fragmented way. In the 20th century, the first significant and structured research on the social significance of sports, on its multiple hi storical, cultural, and organizational aspects came out. From a scientific and academic point of view, the interest in the topic was fundamentally manifested in 1964 at the ICSS (International Committee for Sociology of Sport), which adheres to the ISA (International Sociological Association).

After the Second World War, greater availability of free time, an increase in wealth, enhancement of corporeality and an interest of the media has gradually widened the area of sport practitioners, which from a mainly male activity opened up to the participation of other subjects previously excluded: women, the elderly, disadvantaged people.

One of the most important scholars in the sociology of sports, a German, Klaus Heinemann, had already delimited in the 1980s [4] some models of contemporary sport: among these, the competitive, expressive, and spectacular models. The competitive model is linked to the usual image of sport, and, to some extent, also to the traditional male mentality; it foresees a system of rigid rules, a central importance given to both athletes and fans clubs; the goal is that of victory and education of young people. On the other hand, the expressive model is based on the pleasure of exercising, and its primary purpose is the participant's direct gratification (for example, windsurfing). The spectacular model tends to emphasise fun and entertainment; it is often linked to business or to promotion (even if through advertising) of a personal image or of a company from a commercial point of view.

The aspects highlighted by Heinemann [4] refer to sport in mass society. In the past (especially in the last century), sport was also used to establish the internal consensus within a country or a political system, or to create external propaganda toward other nations. Some of these cases are also in the centre of the present discourse: for example, the male body of a sportsman (which came to coincide with that of a soldier) was represented as a symbol of the strength and power of a nation as in the case of 20thcentury dictatorships in Germany, Italy and the Soviet Union [5]. Thus, sport became an instrument for the dissemination of an ideology. However, in recent decades, sport has lost its "sacred" characteristics just as in the past centuries sport had lost its "religious" aspects, for example, those of the Olympics games. We will develop this discourse further because it was vital in the evolution of masculinity during the 20th century.

Contemporary sport, having lost its religious, political, ideological characteristics, presents itself as a large and complex "rational," organizational, media, commercial machine, with specific inner roles: sponsors, coaches, athletes, advertising promoters, the public, supporters (fans). Within this evolution occurs the change of masculinity in sport, the entry 
of women with different roles (from successful athletes to simple fitness practitioners in a gym), and the change of "gender relations" in sports and society overall.

\section{INSTITUTIONAL DOCUMENTS ON SPORT IN THE EUROPEAN UNION}

Over the past thirty years, the European Union has published many institutional documents on sport, aimed at defining the context of action, purposes, organization, protagonists, public funding related to physical activities and sport.

Among the first documents of the EU was the European Sports Charter, adopted in 1992, which defines Sport as: "all forms of physical activity which, through casual or organised participation, aim at expressing or improving physical fitness and mental well-being, forming social relationships or obtaining results in competition at all levels" [6].

Sport is placed here in a broad framework, which goes beyond the traditional purpose of competition between individuals; sport is also defined as a physical activity that can create advantages on the relational and mental level.

The European system also includes the Eurobarometer [1] (public opinion survey on sport and physical activity in the EU Member States), settled by a structure that carries out periodic surveys among European population (surveys were conducted in 2002, 2009, 2013,2017 ) on the evaluation, support, and development of sport and physical activity promotion policies.

The White Paper on Sport, issued by the EU in 2007 [7], was the next fundamental document on sport with a much broader and more articulated features. The concept of sport (and related physical activities) is further expanded, as among its purposes are the improvement of public health, active citizenship, the development of tolerance, and volunteering; sport also produces positive educational, health, and cognitive effects. The White Paper focuses on the social role of sport, and on its economic and organizational dimensions in Europe. Sport must encourage social inclusion, the integration of minorities, and ensure "equal opportunities." In addition to the practice of physical and sports activities, even women's access to decisional and managerial positions is also promoted, and a higher female media representation in sport is encouraged.

In 2011 the Commission adopted an Opinion entitled "Developing the European Dimension in Sport" [8] providing for specific actions regarding the social role of sport, the economic aspect, and the organization of sport. Based on this, the Council adopted a Resolution on the EU Work Plan for Sport 2011-2014. Following a proposal from the Commission, financial support for sport is now included in the form of a specific chapter in Erasmus+, the EU programme for education training, youth and sport for the period 2014-2020.

\section{THE PRACTICE OF SPORT}

In 2007, according to the Eurobarometer statistics, $40 \%$ of the European population exercised or played sports at least once a week, including $7 \%$ of the population who regularly practiced sport at least five times per week. On the other hand, $46 \%$ of the Europeans never exercised or played sports [1].

However, in the European Union, men exercise or are engaged in other physical activities more than women; the disparity is particularly noticeable in the 15-24 age group, in which young males tend to practice sport with a much higher regularity than young women. Overall, regular sport activity tends to decrease with age. 
Finally, there are considerable differences between various countries of the European Union regarding participation in sport. The countries with the highest proportion of people who exercise or play sports regularly are Finland (69\%), Sweden (67\%), and Denmark (63\%). On the opposite side are Bulgaria, Greece and Portugal, where $68 \%$ of respondents never exercise or play sports.

Men are more likely than women to exercise or play sports; $44 \%$ of men do this regularly, compared to $36 \%$ of women. Men are also more engaged than women in "other physical activities", such as cycling, dancing, or gardening. Concerning "vigorous physical activities" such as lifting heavy things, digging, aerobics or fast cycling, 18\% of men are engaged in these activities compared to $11 \%$ of women. Again, this occurs particularly for younger age groups; $69 \%$ of young men versus $47 \%$ of women pursue these activities. The same happens for moderate physical activities (for example, walking at least 10 minutes a day), also developed more by men than by women.

After analysing the statistical data on sport and physical activity on the European level, we are going to explain the "case" of Italy, a country which is, in any case, significant due to the large number of inhabitants (about 60 million) and its historical and cultural features.

Based on data from ISTAT (the National Statistics Institute) [9], it appears that in 2015, $29.5 \%$ of men played sport continuously, and $11 \%$ practiced it occasionally; for women, the percentages were lower: $19.6 \%$ and $8.1 \%$, respectively. The greater participation of Italian men in sports than women refers to all age groups and education levels [9]. In Italy, some sports are practiced more by women, such as aerobics, dancing, volleyball, water sports; on the other hand, for men, there is great participation in football (which is minimal for women), and high engagement in cycling. Participation in outdoor sports is higher for men, while women are more prevalent in indoor sports (gyms, swimming pools). Among men, there are more present those who practice more than one type of sport, and who practice sport with higher intensity (days during the week or hours during the day).

The reasons for practicing sport differ between Italian men and women. Men exercise mainly for passion or pleasure, women to keep fit, reduce stress, and improve physical appearance. Women, therefore, see more therapeutic powers of sport than men do. Then, a considerable part of the Italian population have never practiced sport; a sedentary lifestyle affects more than half of women (53.2\%), but only $36 \%$ of men.

In conclusion, statistics indicate a reasonably clear picture of gender differences in exercising; men are more present, especially in youth. Later, when the professionally active period of life begins, their active engagement in sport decreases; men are present to a much greater extent than women, especially in football, while, in recent years, there is an increasing presence of women in certain sports or physical activities.

\section{MEN AND SPORTS}

\section{The traditional Profile. The "Jock Culture"}

The analysis of the relationship between men and sport will be presented in its evolution mainly from the middle of the last century to the present day, except for the beforementioned references regarding the meaning of the male body in nationalistic dictatorial systems (fascism, Nazism, communism) especially between the two world wars.

As said, "sport has been perceived as a masculine domain and is one of the primary sites for the social construction of masculinity in contemporary Western Society; Sport can offer 
its young male participants many pleasurable lives. However, it can also create crises within their lives" [10]. This sentence summarizes well the contradictory character of sport for males: on the one hand, it has been a place of domination and construction of masculinity, sometimes in its worst forms; on the other hand, it has also revealed a space for the transformation of the same masculinity towards less aggressive, less misogynistic models, more open to changes and to the modernization of society [11].

A sports and cultural practice called Jock Culture ${ }^{1}$, which preaches the observance of a normative dimension (as it establishes the rules of behaviour and of life) of manhood is cited in the sociological literature for example by Coad [12] as an example of the most extreme forms of machismo. According to several Anglo-Saxon scholars [13, 14], Jock Culture was responsible for many negative approaches towards the masculine role, particularly the aggressive and violent ones, besides perpetuating sexist institutions and values. In the "Sports World" the hyper-masculine values and rituals of the sports arena, of the locker room would have been created, manifested and developed: toughness, excessive emphasis on victory, the "team spirit", the exaltation of bad boys and bullying, the use of homophobia to offend and taunt others, and intolerance against women [15].

The sociological description of Jock Culture recognises the political and cultural atmosphere in the United States and in Europe during the 70s-80s, with an ideological predominance (especially in university classrooms, and often also in media) of "radical" feminism groups, or male pro-feminist and "anti-sexist" groups [16], which tend to attribute to the male, in an absolute way (therefore without internal distinctions), any negative character, both in terms of cultural orientations and material behaviours.

\section{The tRANSITION: FROM the "ALPHA MALE" to the NEW MAN.} METROSEXUALITY AND NEW MALE BODIES

In the 1980s and 1990s, a historical change of masculinity began: a slow process, still in progress, which has its basis in specific economic, political, cultural events; among these, first of all, the transition - which took place throughout Western Europe, in particular in the South - from an agricultural-industrial economy (and culture), composed of poorly educated men dedicated to physical work, to an urban and tertiary sector economy, characterised by men with high education and income who grew up in the era of the intangible activity of services. Consolidated male habits begin to change, from an attitude of traditional indifference to a growing attention to body and health, through the presence of men in the sector of cosmetics, beauty treatments, medicine, and fitness.

In recent years, the Western male perspective has been enriched with new figures, neomovements, and original representations of men. All this has certainly influenced the relationship between masculinity and sport.

The new male figures that emerged in those years presented themselves as alternatives to the so-called "alpha male". Both in sociological literature and media, the term "alpha male" meant the prototype of traditional dominant masculinity, based on precise cultural elements: female subordination, strength, aggression, self-control, power, economic success, bursting sexuality. The followers of Jock Culture were probably "alpha males". But the position of the "alpha male" is difficult to keep in a changing world, in which men, above all, must face new female requests which, among other things, also concern the care and valorisation of the male body. The traditional male, the cowboy, the rough man, the man and the authoritarian father, is not compatible with the modernization of Western society.

${ }^{1}$ Jock is a word that derives from the American slang; it means a person fixated on sports, and also the athlete as opposed to the intellectual. 
Gradually, new male figures appeared, all placed in a wide category (spread in the 80s) of the new man: the man attentive to the expressive-emotional dimension, to the care of children and the relationship with the partner, interested in health, his body and image. It is along this path that in the 90s, emerging from the Anglo-Saxon society, a new figure is identified, the metrosexual, which appears in the de-industrialized metropolis repopulated by the development of services and IT. The metrosexual is the post-Fordism man, wealthy, indifferent to sexual orientation, cared for, a convinced narcissus, fashion addicted, and, above all, detached from the political suggestions that have characterized the movements of men during 70s and 80s which sustained women's struggles as well as the liberation of the gay world [15]. It is far from class distinctions and oppositions: it is also far from the productive logic of the industry, from the workers' movement, and from the symbolic figures of that period: the virtuous wage earner, the disciplined worker, the muscular and powerful proletarian in the defence of his rights; in the post-Fordist society (where the working class has disappeared) individuals, especially males, are transformed from producers to consumers. Moreover, according to some, they even turn into a feminized consumer.

All this has been admirably narrated (better than in many sociological or political works) in the English film "Full Monty", by the director Peter Cattaneo (1997), in which the metallurgical working class, in the period of industrial restructuring, loses all individual and collective certainty. It is one of the many forms of the crisis of traditional masculinity, where workers laid off by the company no longer play sports, nor have intimate relationships with their partners disappointed and impoverished by the absence of male income in the family. In this state of emergency, and the due to the disappearance of the traditional Welfare guarantees, six workers decide to redeem themselves, even to earn a few pounds, choosing to perform in a full striptease show. In this situation, men become aware of their body, understand that industrial production is no longer needed, and thus decide to get naked, physically and symbolically, in front of the ironic and amused looks of the female audience who sees the possibility of its revenge [16].

In the following years, we witness a sort of transformation, a recovery, a redemption of men, which is manifested in various forms. Throughout Europe, there has been a rediscovery of the male body, no longer in ideological or political terms, nor trying to recover the athlete's sacred body, but there is a conversion to the individualistic ideology of fitness, to live well and strong, without ethical purposes. "Self-care" is the imperative of this new phase, with all the narcissism, cosmetic surgery, image care, attention to fashion and men's help magazines (one of the best-known examples is Men's Health). The man is attracted to the commercial circuit of mass consumerism; a specific market for male products is created [17]. The same male body (also in the sports field) increasingly enters the media; men's bodies are shown in the cinema, in advertising videos for dietary cures and gyms, in magazine pages [18].

\section{Men ANd WOMEN TOgether IN SPORT. THE CROSSfit}

Sport is a place where the traditions that support the differences between males and females can be consolidated. At the same time, however, breaking experiences, conflict, challenge and redefinition of the dominant ideas of gender can emerge in sport. For example, in historically men's disciplines such as boxing, rugby, and in male-dominated sports such as football, openness to women has generated a challenge for gender norms, creating multiple conflicting discourses. Women who play these sports contrast with the adequate male body image, and the male qualities involved. At the same time, the prevailing representation of woman is also questioned. Female sports can encourage a redefinition of the usual gender differences, associating characteristics considered to be both male and female in the same activity [3]. 
From this point of view, for example, the experience of Crossfit is very interesting, a practice that is rapidly spreading, in which men and women compete together in different types of sports and they train together, and do the same exercises. With Crossfit, the joint male and female participation in sport becomes a fact that is not accidental, but planned and organized [3].

The Crossfit games ${ }^{1}$ present both two distinct competition categories for men and women, and a mixed category. This has contributed to redefining the concept of masculinity and femininity in sport. Crossfit is a genderless practice, not to uniform differences, but as a reconfiguration of rigid definitions of masculinity and femininity [3]. For example, the same concept of strength, when this is no longer exclusively masculine, can become a category for a different way of perceiving oneself, and also can generate new relations between genders. Crossfit offers experiences and relationships capable of reconfiguring the categories of gender identities in the first place in the way of seeing and considering one's own personal identity. This practice aims to recognize the athlete's identity outside the typical parameters of hegemonic masculinity [3]. So, even within sport, dominant male discourses and prejudices have been deconstructed, dismantled, thus opening the way for change [3].

\section{SPORT, MALE BODY AND MEDIA}

Everything was deeply reflected in the transformations that occurred in sport, which would not have been possible if the phenomena mentioned above had not occurred in the outside world, which have characterized the lives of men and women in the last forty years, taking into particular consideration also the so-called "masculinity crisis", which has been much talked about [16], both in university classrooms ${ }^{2}$ and in media.

To fully understand the recent transformations of the male body, and of men's attitudes towards sport, it is important to approach the existing ideologies between the two world wars, and also during the period after the first world war, regarding the meaning of the male body in the twentieth century. An athlete's body, as mentioned above, was considered the "male body of the nation" [19]; this ideological operation was perfected in the era of nationalisms, especially between the two world wars, and continued in part in the following decades, until the 1960s. In this context, sport is not just competition, movement, expressiveness; sport is also understood as "social hygiene", that is, rules that not only athletes, but everybody must abide by. The health of the athlete's body (especially if male) is identified with the physical and moral health of a nation. The nation-body becomes a mythical, heroic, pure body, eventually - a "sacred" body [19].

Today the athlete's body is not identified with the country to which it belongs, but with the sports club that pays the best; his body has become a surface filled with sponsors and advertising. From a heroic-sacral body, the male athlete's body becomes a "television body", or rather "media body". The context in which this process takes place is globalization: sport is no longer linked to a nation. Today the relationship between national male models and athletes of a country has dissolved. National masculinities are confronted with international or global sporting models tout-court.

These athletes' lifestyles remind more of the new man (e.g. the metrosexual) than the traditional macho. Today's male athletes are mirror men ("men in front of the mirror", who love to admire themselves and be admired), consumers, elegant, playboys, very present

\footnotetext{
${ }^{1}$ Crossfit games have been held annually since 2002; everyone can enter competition through a qualification system that implies winning an intermediate step: the Regionals.

${ }^{2}$ One example is the vast production of Men's Studies from the 70s; it was a current born from an important and vast literature of Gender Studies and Women's Studies, originating in the Anglo-Saxon society, especially Northern American, and later spread to other countries from Central and Northern Europe (France, Germany, Sweden), and lately also in Italy and in Eastern Europe. These are some of the basic texts: Elias, Dunning, 1986; Brod, 1987; Kimmell, 1987; Seidler, 1989; Giddens, 1992; Connell, 1995; Bourdieu, 1998 ; Spallacci, 2012.
} 
in the media, with exasperating care of their body not only in terms of muscles. While the athlete representing the "body of the nation" was a champion of strength and rigor, of high morality, dedicated to sacrifice (an example being the Italian Pietro Mennea ${ }^{1}$ ), instead the sportsmen of today are boys with whom one can identify, at the mass level, as true media products [19].

The model that currently best represents the new "metrosexualized" athlete is a young player (especially the Italian players at the beginning). Beautiful, worldly, with tattoos, earrings, necklaces; he is a star, wearing personalized shoes to advertise a brand, posing for calendars, entering the star system which revolves around the "sport show". His photos appear in gossip magazines; he is an idol to whom a lot of love is attributed; often his partner is a movie star. The mix between the athlete and the fashion world leads to the formation of a male model with characteristics previously attributed to the female world only. Today's athlete is often present in men's magazines, not in pornographic or macho ones, but those to help men, a new editorial line very popular among young men, dynamic and attentive to "self-care".

\section{CONCLUSIONS}

Nowadays, there are many dimensions of sporting masculinity. Any monothematic representation, such as that of the first sociology of gender, linked to the traditional stereotypes of the 1960s and 70s, does not take into account the recent evolution and male change, which has provided a multiplicity of models also in the sports field. Thus, also sport, initially a place to marginalize female activity, and to build traditional dominant masculinity, has proved to be, like many other social organizations (family, work, school), a place of contradiction for the man and of transformation of his identity. We are facing a dialectical process: sport influences gender identities, but it is also determined by them. So even within sports, dominant male discourses and prejudices have been deconstructed, shattered, thus opening a way for change.

Sports athletes can become models of masculinity to which especially young people, and, to some extent, even adults can refer to [19]. Desacralisation of sport, a decrease in both hyper-masculine costumes and the practice of the Jock Culture along with mediatisation of the athlete's body has brought the sports world and athletes closer to daily life, habits, aspirations - especially in the context of consumption and the self-representation - to the large mass of the male population. The process is in progress and will go on; we will not return to the "body of a nation". The sirens of consumerism are appealing, and it is difficult to resist their seduction.

\section{REFERENCES}

[1] Sport and physical activity (Special Eurobarometer 472). Brussels: European Commission; 2018. [Available at https:// data.europa.eu/euodp/en/data/dataset/S2164_88_4_472_ENG] [Accessed on 7 April 2020].

[2] Connell RW. Masculinities, Cambridge: Polity Press; 1995.

[3] Bifulco L, Tuselli A. Corpi sportivi e identità di genere. Il Crossfit [Sportspersons bodies and gender identity. Crossfit]. La Camera blu. 2017;17:254-282. Italian.

[4] Heinemann K. Practical Orientation and Function of Sport Sociology. Int Rev Sport Soc. 1983;18(1):21-34. https:// doi.org/10.1177/101269028301800102

[5] Mosse G. The Image of Man. The creation of modern masculinity. New York: Oxford University Press; 1996.

[6] Council of Europe - Committee of Ministers. Recommendation no. R (92) 13 REV of the committee of ministers to member states on the revised European Sports Charter. 1992. [Available at https://rm.coe.int/16804c9dbb] [Accessed on 2 April, 2020].

[7] Commission of the European Communities. White Paper on Sport (white paper). Brussels: COM 391 final; 2007. [Available at https://eur-lex.europa.eu/legal-content/EN/TXT/?uri=CELEX\%3A52007DC0391] [Accessed on 2 April, 2020].

\footnotetext{
${ }^{1}$ Pietro Mennea was an Italian sprinter athlete born in 1952 and died in 2013. He was Olympic champion of the 200 meters, and European
} record holder from 1979 to 1996. 
[8] European Economic and Social Committee. SOC/413. Developing the European Dimension in Sport - Opinion. Brussels: COM 12 final; 2011. [Available at http://eose.org/wp-content/uploads/2014/03/opinion_eesc_communication_ european_dimension_sport.pdf] [Accessed on 2 April, 2020].

[9] Istituto Nazionale di Statistica (ISTAT). La pratica sportiva in Italia - Anno 2015 [Sports practice in Italy - Year 2015]. Roma: ISTAT; 2017. Italian.

[10] Drummond JNM. Sport and image of masculinity: The meaning of relationship in the life course of "elite" male athletes. J Men Stud. 2002;10(2): 129-141. https://doi.org/10.3149/jms.1002.129

[11] Messner M. Power at play. Boston: Beacon Press; 1992.

[12] Coad D. The Metrosexual. Gender sexuality and sport. Albany: State University of New York Press; 2008.

[13] Runfola R, Sabo DF. Jock: Sports and Male Identity. Englewood Cliffs: Prentice-Hall; 1980.

[14] Lypsite R. Sportsworld: An American dreamland. New York: Quadrangle/New York times Book Co.; 1975.

[15] Fagiani ML. Metrosexual. Mascolinità e suggestioni urbane [Metrosexual. Masculinity and urban suggestions]. In: Fagiani ML, Ruspini E, editors. Maschi alfa, beta, omega. Virilità italiane tra persistenze, imprevisti e mutamento [Alpha, beta, omega males. Italian virility between persistence, unexpected events and change]. Milano: Franco Angeli; 2011, 67-94. Italian.

[16] Spallacci A. Maschi [Males]. Bologna: il Mulino; 2012. Italian.

[17] Spallacci A. Maschi in bilico. Uomini italiani dalla ricostruzione all'era digitale [Males in balance. Italian men from reconstruction to the digital age]. Milano-Udine: Mimesis edizioni; 2019. Italian.

[18] Ruspini E, editor. Uomini e corpi. Una riflessione sui rivestimenti della mascolinità [Men and bodies. A reflection on the coatings of masculinity]. Milano: Franco Angeli; 2009. Italian.

[19] Boni F. Sport, mascolinità e media [Sport, masculinity and media]. In: Dell'Agnese E, Ruspini E, editors. Mascolinità all'italiana. Costruzioni, narrazioni, mutamenti [Italian masculinity. Constructions, narratives, changes]. Milano: UTET; 2007, 79-102. Italian. 